\title{
Optimizing Mixture Composition to Improve the Performance of Porous Asphalt for Wearing Course as an Environmentally Friendly Road Construction Material
}

\author{
Ika Sulianti $^{1, \text { a })}$, Amiruddin Amiruddin ${ }^{1}$, Ibrahim Ibrahim ${ }^{1}$ and A.Subrianto ${ }^{1}$ \\ ${ }^{1}$ State Polytechnic of Sriwijaya, Jl. Srijaya Negara Bukit Besar Palembang 30139, \\ South Sumatera - Indonesia \\ a) Corresponding author: ardiansyahwelly74@gmail.com
}

\begin{abstract}
Porous asphalt is an alternative in flexible pavement which is considered to make water seep into the soil. In previous research have been tested the mixture of porous asphalt that meets porous asphalt porosity requirements, but found the weaknesses that the stability is still lower than the standard required. Based on result obtained before, the study is aimed at investigating the use of mixture composition variable with different percentages until the optimal conditions were obtained, namely making a normal mixture, $15 \%, 18.75 \%, 22.5 \%, 26.25 \%, 30 \%$ as sand composition reduction. The percentage of sand reducted from previous composition with different asphalt variations. Tests are carried out using the Marshall method. Sequence of tests show that the materials used for experiment meet the requirement. Optimum Asphalt Content obtained for the mixture are $6 \%$ of the total mixed weight. The best Marshall characteristics for AC-WC porous asphalt obtained are at the percentage of $26.25 \%$ sand reduction.
\end{abstract}

Keywords: porous asphalt, stability, sand reduction

\section{INTRODUCTION}

Construction development demands additional infrastructure, including highway facilities. However, this phenomen causes a reduction of green areas which have an impact on the lack of water catchment areas. Therefore, the construction of highways in Indonesia in addition to being required to improve the level of safety and comfort is also required to develop environmentally friendly roads.

Flexible Pavement is a pavement system where the construction consists of several layers. Each pavement layer generally uses materials and requirements that are different according to its function, namely, to spread the wheel load of the vehicle in such a way that it can be held by the subgrade within its carrying capacity limit.

Porous asphalt is an alternative in flexible pavement which is considered to enable water seep into the soil so that the manufacture of ground water can continue to occur. In addition, porous asphalt is an alternative to improve road safety and noise reduction. Porus asphalt is designed to obtain the large pores to continue the flow of water to the side channels and a water-resistant base layer to prevent water from seeping into the subbase layer and the body of the road, so that the inundation of the inadequate slope can be overcome. This often happens after rain that can disrupt the smooth flow of traffic. 
In Japan, Netherlands and a number of other countries have used porous asphalt as the main road [1] and [2], including in Indonesia, Australian porous gradation is generally first applied to the Jagorawi toll road project and the Tangerang-Jakarta toll road, in 1997. Porous asphalt is a mixture of asphalt with certain aggregates which are designed after being compacted to have air pores ranging from $20.00 \%$. The main problem found in a single function asphalt is caused by clogging of the cavity by dust. This problem can be reduced by applying two layers of porous asphalt. As illustrated in [3].

Porous asphalt is asphalt mixed with certain aggregates which after compacting have $20 \%$ air pores and generally have a lower Marshall stability value than asphalt concrete which uses tight gradations, Marshall stability can increase when open gradations are used more smooth fractions [4].

Porous asphalt is an alternative to improve road safety and reduce noise. Asphalt pavement is designed to obtain a large pore to continue the flow of water to the side channel and the waterproof coating to prevent water from seeping into the subbase layer and the road side so that puddle above the road surface often occurs after rain and disrupts the smooth flow of traffic can be minimized. This condition is possible because the gradation used is an open gradation which has a coarse aggregate fraction of not less than $85 \%$ of the total mixture weight. In previous research have been tested the mixture of porous asphalt that meets porous asphalt porosity requirements, but there are weaknesses in the resulting stability is still lower than the standard. This stability characteristic is very important in the asphalt strength structure used for various road. In this study, the researchers wanted to proceed to the next stage to increase the value of stability of porous asphalt.

\section{RESEARCH METHODOLOGY}

This study continued the previous study, through the standard agregate physical tests and also asphalt tests. Based on result obtained before, the study is aimed at investigating the use of mixture composition variable with different percentages until the optimal conditions were obtained: making a normal mixture, $15 \%, 18.75 \%, 22.5 \%, 26.25 \%, 30 \%$ with different asphalt variations. Tests were performed using the Marshall method.

This research was conducted at State Polytechnic of Sriwijaya, Department of Civil Engineering Laboratory and material was obtained around Palembang city.

\section{THE RESULTS AND DISCUSSION}

In this study, the aggregate used in this study was coarse aggregate and fine aggregate. Coarse aggregate in the form of broken stone originating from Lahat and fine aggregate in the form of sand comes from Tanjung Raja. The test results can be explained in Table 1.

TABLE 1. Results of Testing the Physical Properties of Aggregates

\begin{tabular}{cccccc}
\hline No & Tests & Unit & Result & Specification & Information \\
\hline $\mathbf{A}$ & Fine aggregate & - & & & \\
\hline $\mathbf{1}$ & Bulk specific & - & 2.50 & - & Satisfied \\
\hline $\mathbf{2}$ & Apparent specific & & 2,30 & - & Satisfied \\
\hline $\mathbf{3}$ & SSD & & 2,35 & - & Satisfied \\
\hline $\mathbf{4}$ & Specific gravity & & 2,50 & - & Satisfied \\
\hline $\mathbf{5}$ & Water content & $\%$ & 2,04 & - & Satisfied \\
\hline $\mathbf{6}$ & Mud content & $\%$ & 0,77 & $<5$ & Satisfied \\
\hline $\mathbf{B}$ & Coarse Aggregate $\mathbf{1} / \mathbf{2}$ & & & & \\
\hline $\mathbf{1}$ & Bulk specific & & 2.58 & - & Satisfied \\
\hline $\mathbf{2}$ & Apparent specific & & 2.77 & - & Satisfied \\
\hline $\mathbf{3}$ & SSD & & 2.66 & - & Satisfied \\
\hline $\mathbf{4}$ & Specific gravity & & 2.70 & - & Satisfied \\
\hline $\mathbf{5}$ & Mud content & & 1,87 & $<1$ & Satisfied \\
\hline
\end{tabular}




\begin{tabular}{lccccc}
\hline $\mathbf{6}$ & Abrasion & $\%$ & 22.52 & $<50$ & Satisfied \\
\hline $\mathbf{7}$ & Water content & $\%$ & 3.13 & - & \\
\hline
\end{tabular}

The asphalt used in this study was asphalt with the grade 60/70 which has met the AASTHO specifications. Tests which were performed on the asphalt included asphalt penetration, flash point,softening point, ductility and specific gravity which shown at Table 2 .

TABLE 2. Asphalt Testing Results

\begin{tabular}{ccccccc}
\hline No. & Tests & Unit & \multicolumn{2}{c}{ Specification } & Result & Information \\
\cline { 3 - 5 } & & Min & Max & & \\
\hline $\mathbf{1}$ & $\begin{array}{c}\text { Penetration at } 25^{\circ} \mathrm{C} 100 \\
\text { gram } / 5 \text { second }\end{array}$ & Mm & 60 & 79 & 74,255 & Satisfied \\
\hline $\mathbf{2}$ & Softening point & ${ }^{\circ} \mathrm{C}$ & 48 & 58 & 53,75 & Satisfied \\
\hline $\mathbf{3}$ & Flash point & ${ }^{\circ} \mathrm{C}$ & 200 & - & 325 & Satisfied \\
\hline $\mathbf{4}$ & Ductility & $\mathrm{Cm}$ & 100 & - & 130 & Satisfied \\
\hline $\mathbf{6}$ & Specific gravity & $\mathrm{gr} / \mathrm{cc}$ & 1 & - & 1,07 & \\
\hline
\end{tabular}

Testing was performed using two samples with different blows, the first sample 35 blows and the second sample 50 blows. The results of testing with 35 blows are shown in Table 3 and Table 4.

TABLE 3. Results of Marshall Standard Test

\begin{tabular}{ccccccc}
\hline No. & Parameters & Specification & \multicolumn{4}{c}{ Asphalt content to mixture } \\
\cline { 3 - 6 } & & & $\mathbf{5 \%}$ & $\mathbf{5 , 5 \%}$ & $\mathbf{6 \%}$ & $\mathbf{6 , 5 \%}$ \\
\hline $\mathbf{1}$ & VMA & Min. $15 \%$ & 10,822 & 12,257 & 17,123 & 18,057 \\
\hline $\mathbf{2}$ & VIM & $3-5 \%$ & 2,552 & 3,035 & 7,388 & 7,419 \\
\hline $\mathbf{3}$ & VFA & Min. $65 \%$ & 76,705 & 77,464 & 56.866 & 59,513 \\
\hline $\mathbf{4}$ & Stability & $800 \mathrm{~kg}$ & 1782,797 & 1248,610 & 2034,265 & 1877,180 \\
\hline $\mathbf{5}$ & Flow & $2-4 \mathrm{~mm}$ & 4,598 & 5,436 & 6,912 & 4,439 \\
\hline
\end{tabular}

Based on the results of the tests, asphalt content that has meet the requirements of Bina Marga 2010 revision 3 was at $5.5 \%$ and $6.5 \%$. Then asphalt optimum content used in this study is $6 \%$.

TABLE 4. Optimum asphalt content determination

\begin{tabular}{cccccc}
\hline Parameters & Specification & \multicolumn{4}{c}{ Asphalt content } \\
\hline & & $\mathbf{5 \%}$ & $\mathbf{5 , 5 \%}$ & $\mathbf{6 \%}$ & $\mathbf{6 , 5 \%}$ \\
\hline VMA & Min $15 \%$ & & & & \\
\hline VIM & $3-5 \%$ & & & \\
\hline VFA & Min $65 \%$ & & & \\
\hline Stability & $800 \mathrm{~kg}$ & & & \\
\hline Flow & $3-4 \mathrm{~mm}$ & & & \\
\hline
\end{tabular}

Further, the testing was performed on each asphalt content. There were 12 test specimens with percentage of fine aggregate reduction of $0 \% ; 15 \% ; 18.75 \% ; 22.5 \% ; 26.25 \%$ and $30 \%$ each of 3 test pieces. The asphalt content used is $6 \%$. 


\section{Analysis of Porous Asphalt Mixtures}

Mixture analysis with different aggregate gradations is done by reducing the percentage of fine aggregate by $15 \%$, $30 \%, 45 \%$ and $60 \%$ which will then be distributed to the amount of coarse aggregate percentage to the total weight of the mixture to obtain porous asphalt with the use of optimum asphalt content (OAC) of $6 \%$.

VIM (voids in the mix) is the number of pores between aggregates covered with asphalt expressed as a percentage of the volume of solid asphalt. In accordance with general specifications in the field of roads and bridges, the Department of Public Works (2010), VIM for a mixture of asphalt concrete - Wearing Course (AC-WC) has a limit between $3-5 \%$. VIM is needed to place aggregate grains due to additional compaction caused by traffic load repetitions, or asphalt sites become soft due to increased temperatures. VIM that is too large in a lack of water and air tightness which can cause the pavement layer to be easily oxidized and damaged. VIM that are too small cause the pavement bleeding when the temperature increases.

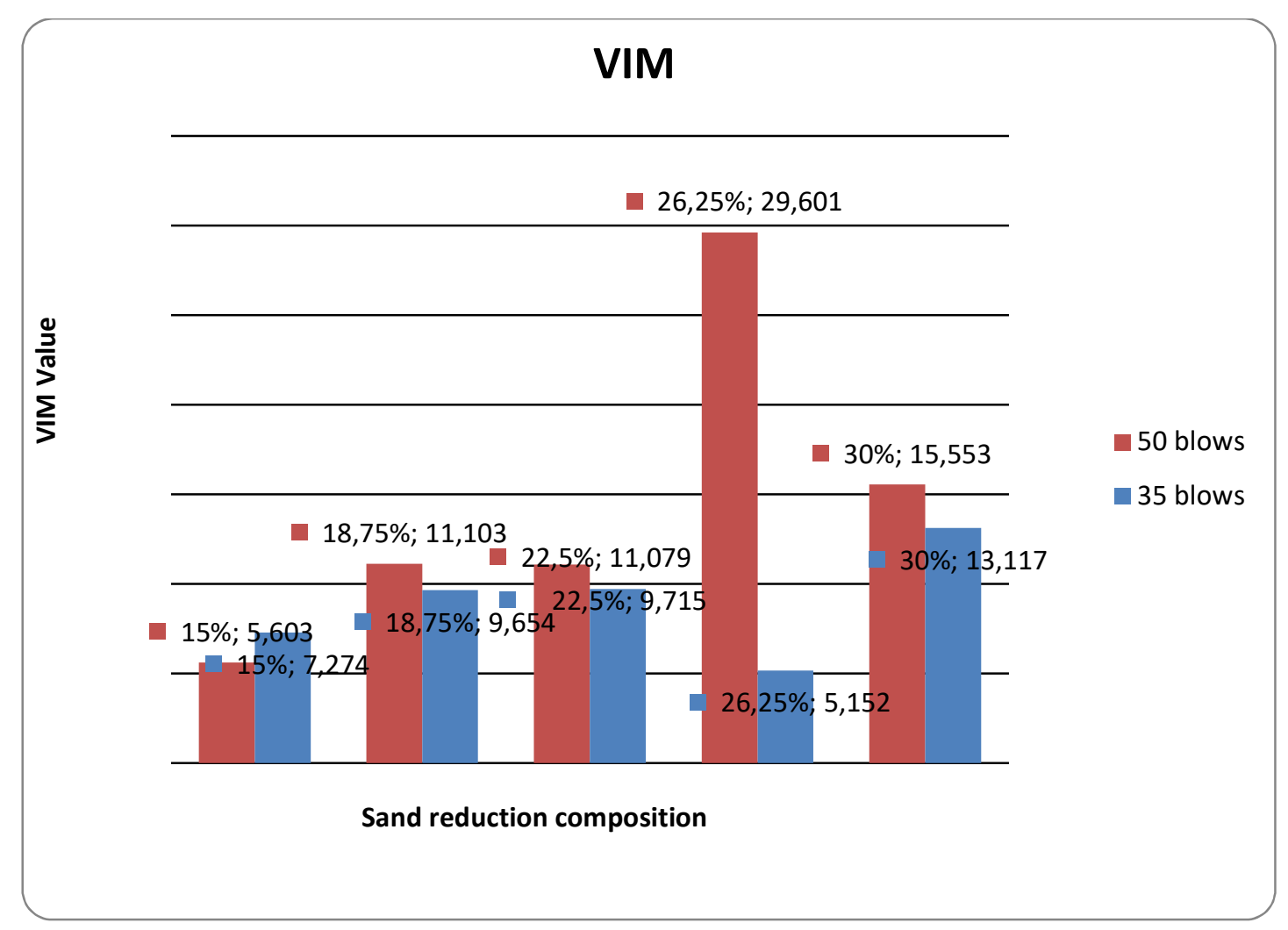

FIGURE 1. Mixed Analysis of VIM

From the figure 1, the results of the voids in the mixture are obtained according to the number of blows, which are 35 and 50 times respectively in variations of $15 \%, 18.75 \%, 22.5 \%, 26.25 \%, 30 \%$. VIM values tend to increase with percentage increases. In porous asphalt, the value of VIM increases will more quickly absorb water from the road surface and drain it to the channel beside the road. If the VIM value in the mixture is too small, the water flowing into the asphalt mixture slows down.

Voids in the minerals aggregate (VMA) is the number of pores between aggregate grains in solid asphalt concrete expressed as a percentage of the volume of asphalt concrete mixture. The minimum VMA value is determined by the Department of Public Works (2010), which is 15\% because if VMA is too low, bleeding can occur. Figure 2 describes the test result for VMA. 


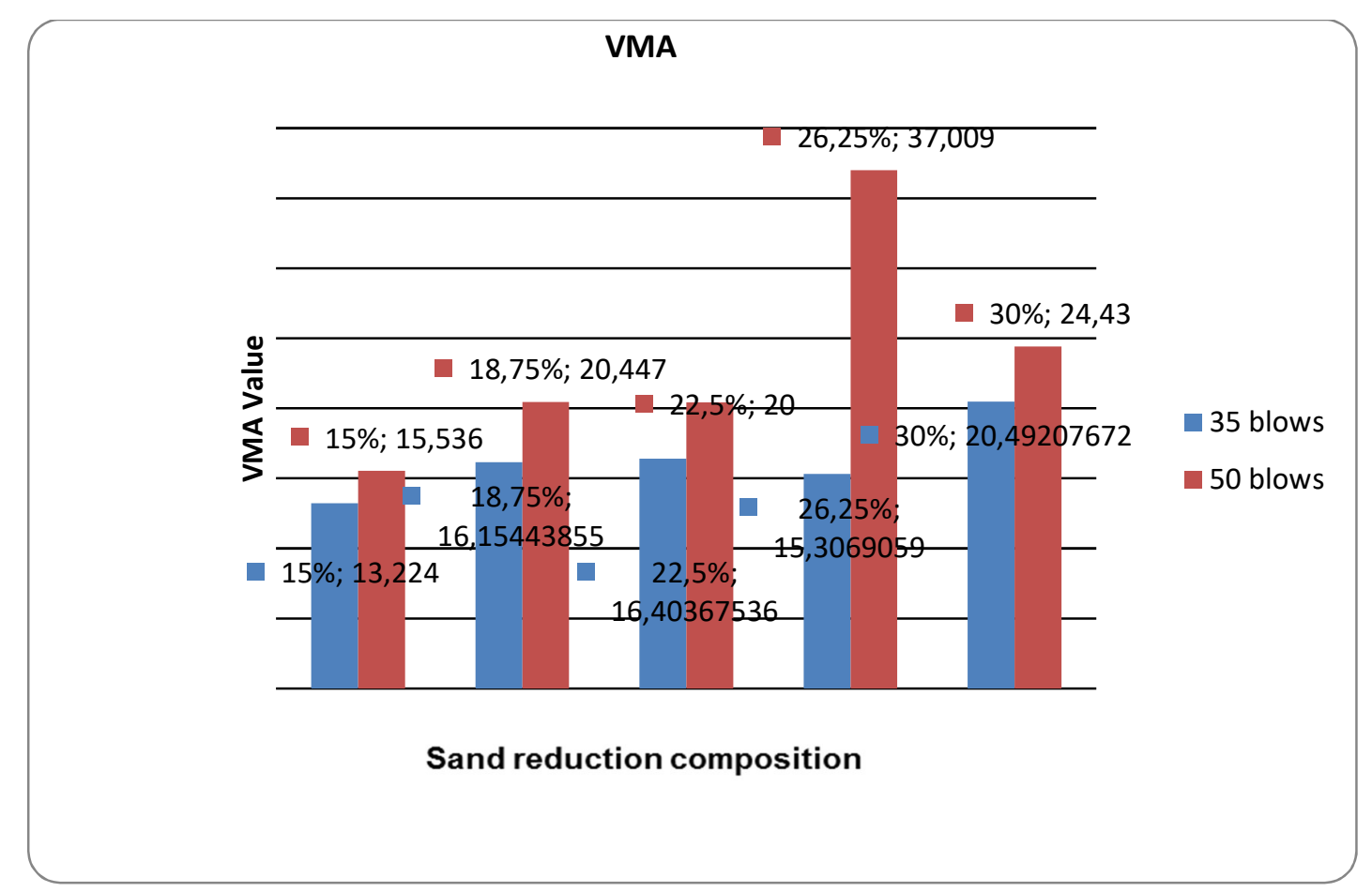

FIGURE 2. Mixed Analysis of VMA

Based on Figure2, the results of the voids in the mineral aggregate are obtained according to the number of blows, which are 35 and 50 blows respectively in variations of $15 \%, 18.75 \%, 22.5 \%, 26.25 \%, 30 \%$. VMA values tend to increase due to the possible nature of the asphalt mixed will increase the hardness and softening point of the asphalt so that the optimal temperature required for compaction will also change.

VFA (voids filled by asphalt) is the pore volume of asphalt concrete filled with asphalt. VFA is a part of VMA filled with asphalt not including asphalt absorbed by aggregate thus, the asphalt filling VFA is asphalt which functions to bind aggregate grains in solid asphalt concrete. The Department of Public Works (2010) requires a minimum value of $65 \%$ for VFA. Figure 3 explains the results of the cavities in the mixture are obtained according to the number of blows, which are 35 and 50 times respectively in variations of $15 \%, 18.75 \%, 22.5 \%, 26.25 \%, 30 \%$. Reduction of fine aggregate percentage results in VFA decrement. The decrease in VFA value is caused by the increase in VMA value. With the same amount of asphalt, if the value of the inter aggregate cavity (VMA) is greater, the percentage of the cavity filled by asphalt (asphalt covering the aggregate) will be smaller. 


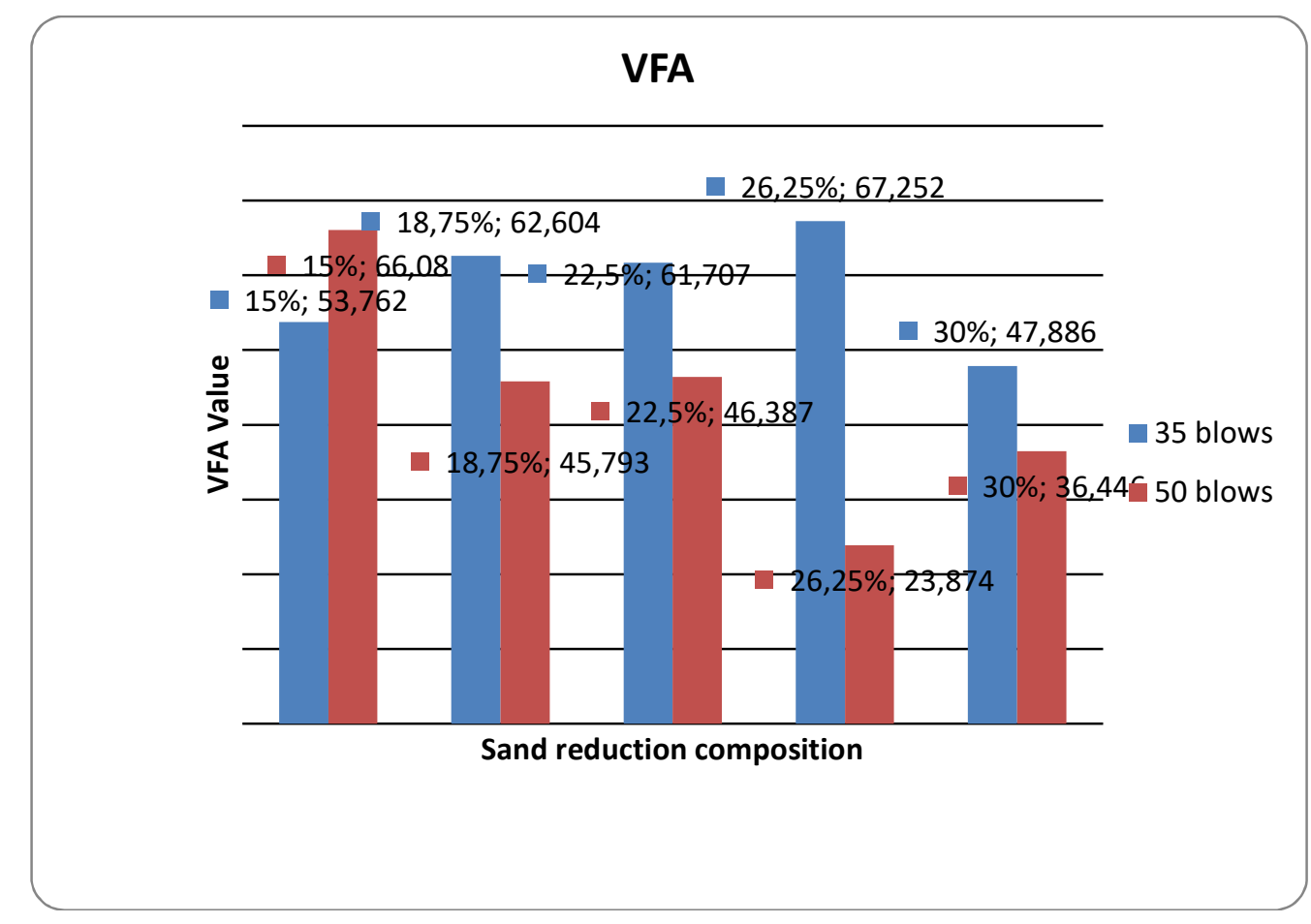

FIGURE 3. Mixed Analysis of VFA

Stability test was used to measure the maximum ability of asphalt concrete to receive loads until plastic melting occurs. The stability value obtained from the reading of the stability measuring watch obtained from the reading of the stability measuring watch multiplied by the calibration value of the proving ring and corrected by the correction number due to the variation in thickness of the test object. The minimum stability value implied by Bina Marga is 800 $\mathrm{kg}$.

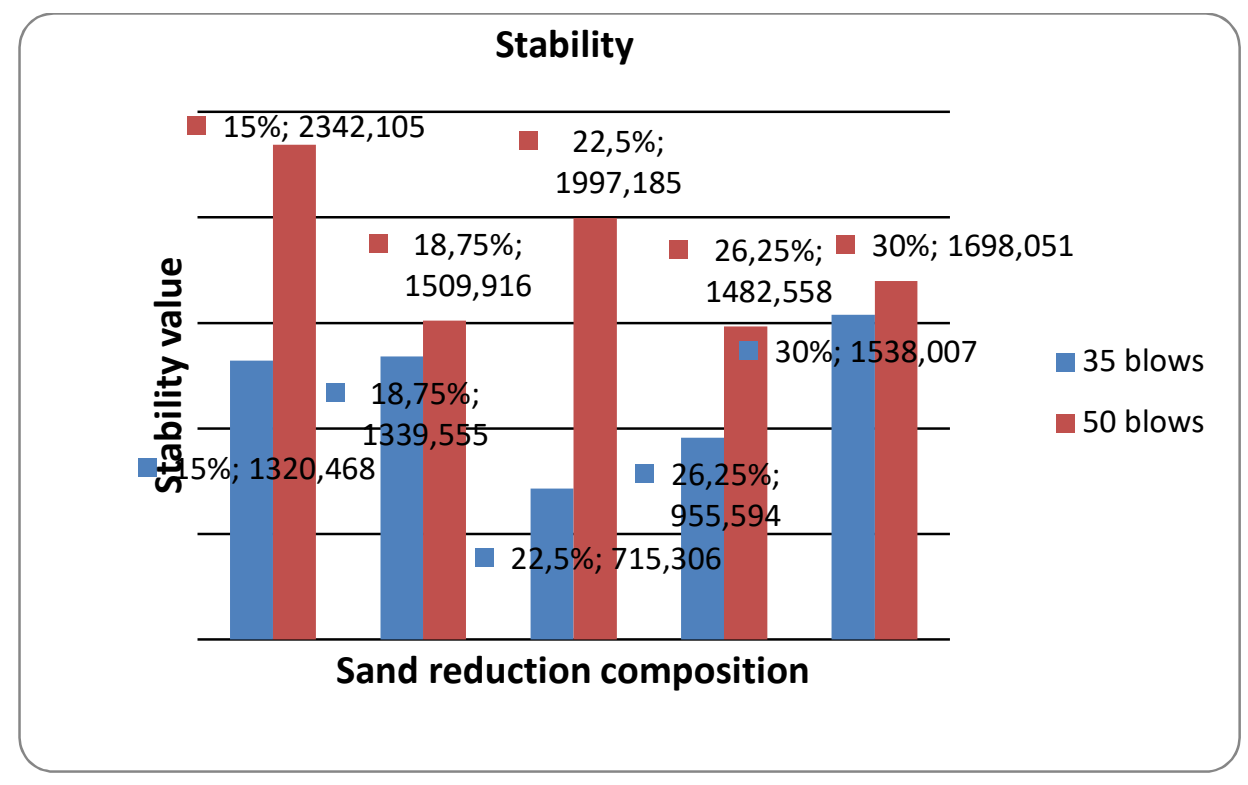

FIGURE 4. Mixed Analysis of stability 
Stability is affected by internal friction between aggregates and asphalt cohesion properties. The nature of asphalt cohesion is affected by asphalt penetration, changes in viscosity due to temperature, loading rate, chemical composition of asphalt, effects and asphalt lifetime. Picture 4 shows the value of stability tests by variation of sand reduction composition. High stability is needed for high traffic otherwise for light traffic is not required high stability. From the tests obtained he highest stability value is at $15 \%$ percentage of 50 blows at $2242.11 \mathrm{~kg}$ and at 35 blows of $30 \%$ percentage at $1538.01 \mathrm{~kg}$. All of composition meet the requirement of $800 \mathrm{~kg}$ minimum for AC WC.

Flow is the amount of deformation or change in shape due to load. Flow values are obtained from flowmeter gauge which are expressed in $\mathrm{mm}$ unit. Test result shown at figure 5 tells that flow values increase due to the decrement of fine aggregate. This can be caused because the mixed mineral asphalt arrangement changes and makes the physical properties of the asphalt increasingly hard and the softening point increases so that the mixture becomes less flexible.

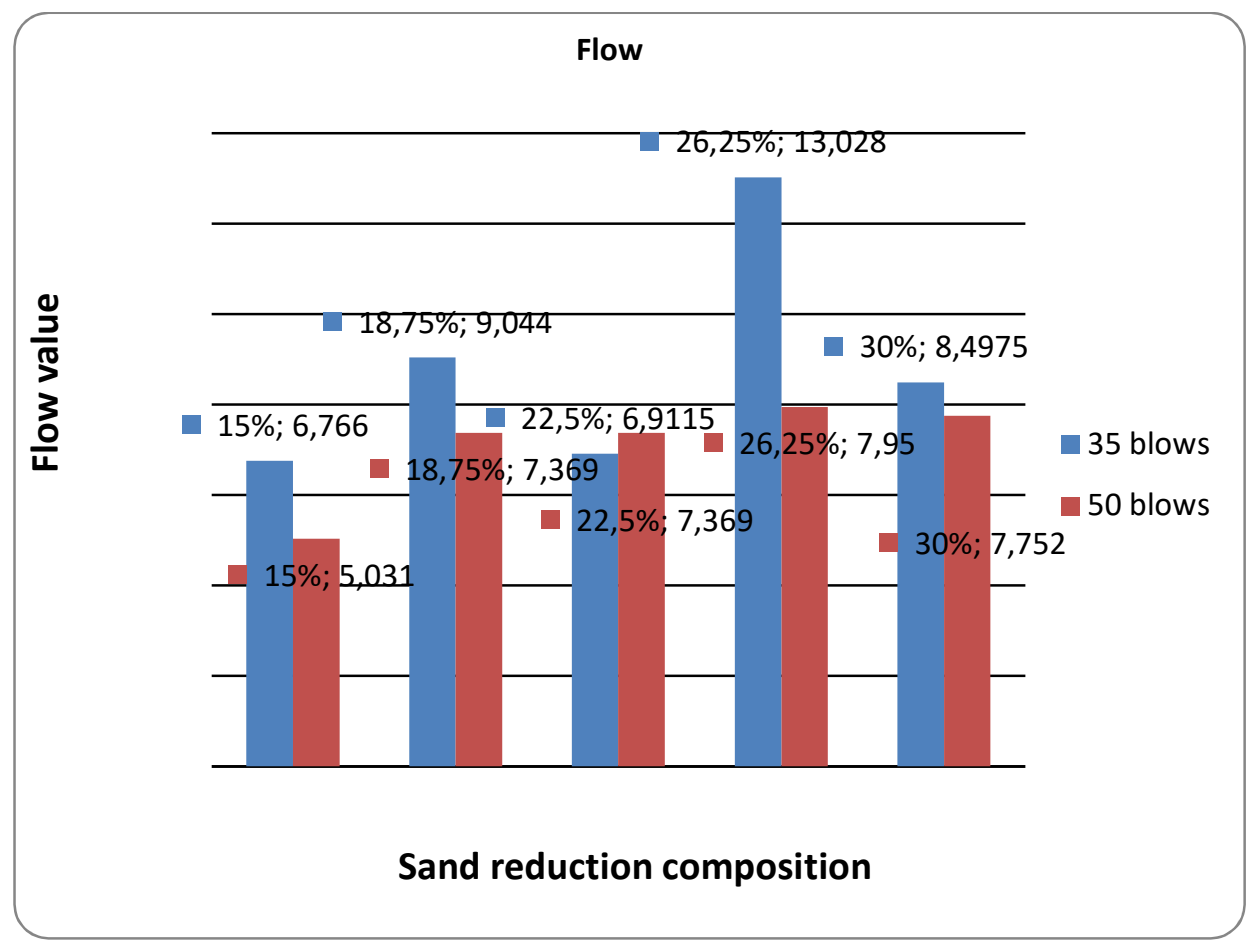

FIGURE 5. Mixed Analysis of flow

\section{CONCLUSION}

This study has completed the testing of materials, the preparation of the mix design test in the laboratory scale, and then can be concluded as follows:

1. Aggregate and asphalt that have been tested meet the standards that are required by Bina Marga.

2. Optimum Asphalt Content obtained for the mixture are $6 \%$ of the total mixed weight.

3. The maximum porosity obtained is $29.610 \%$, this meets the standard recommended, which is $20 \%$, this occurs in 50 blows tests.

4. The best Marshall characteristics for AC-WC porous asphalt obtained are at the percentage of $26.25 \%$.fine aggregate reduction.

5. The stability value obtained for each reduction in the percentage of sand shows a decrease in the value of stability as well as the treatment of the number of blows, the more the number of blows, the higher the value of stability. 
It is to continue the study using various type of material stockpile, considering the small volume, so that from our research we still arrange the composition needed to meet the standards. Therefore, if in large quantities it is necessary to have accuracy in the application later. The results showed a decrease in stability with increasing porosity or void. Further research is needed for certain compositions in order to obtain stable stability and sufficient porosity. This asphalt layer must be placed above the layer below which is guaranteed to be waterproof so that the water does not enter the foundation layer of the road.

\section{REFERENCES}

[1] M. Miradi, A.A.A. Moleenar, M.F.C van de Ven, Performance modeling of porous asphalt concrete using artificial intelligence, Road Materials and Pavement Design, ICAM 2, pp.263-280, 2009.

[2] Cabrera, J.G \& Hamzah, M.O, “Aggregate Grading Design for Porous Asphalt”, Proceeding of, Symposium, University of Leads, 1991.

[3] Katsuji Nishijima, Shiego Higashi and Masaki Ikeuchi, Development of re-paved porous asphalt pavement method for reconstructing existing dense graded asphalt pavement into porous asphalt pavement using the inplace surface recycling method, Proceeding of $13^{\text {th }}$ Conference of the Road Engineering Association of Asia and Australasia (REAAA), 9-15, 2009.

[4] Borchove Van, G.G, "Twinlay, A New Concept of Drainage Asphalt Concrete", Proceedings of Eurasphalt Eurobitume Congress. Starbourg. France, 1996 